\title{
Impact Resistance of Lightweight Hybrid Structures for Gas Turbine Engine Fan Containment Applications
}

\author{
Mohan G. Hebsur, Ronald D. Noebe*, and Duane M. Revilock \\ NASA Glenn Research Center, Cleveland, OH 44135
}

\begin{abstract}
$\underline{\text { Abstract }}$
The ballistic impact resistance of hybrid composite sandwich structures was evaluated with the ultimate goal of developing new materials or structures for potential gas turbine engine fan containment applications. The sandwich structures investigated consisted of GLARE ${ }^{\circledR}-5$ laminates as face sheets with lightweight cellular metallic materials such as honeycomb, foam, and lattice block as a core material. The impact resistance of these hybrid sandwich structures was compared to GLARE-5 laminates and 2024-T3 Al sheet, which were tested as a function of areal weight (material thickness). The GLARE-5 laminates exhibited comparable impact properties to that of 2024-T3 Al at low areal weights, even though there were significant differences in the static tensile properties of these materials. The GLARE-5, however, did have a greater ballistic limit than straight aluminum sheet at higher areal weights. Furthermore, there is up to a $25 \%$ advantage in ballistic limit for the GLARE5/foam sandwich structures compared to straight 2024-T3 Al. But no advantage in ballistic limit was observed between any of the hybrid sandwich structures and thicker versions of GLARE-5. Recommendations for future work are provided, based on these preliminary data.

*Contact for all correspondence:

Ronald Noebe, NASA Glenn Research Center, M.S. 49-3, 21000 Brookpark Rd., Cleveland, OH 44135 Phone: 216.433.2093 Fax: 216.977.7132




\section{Introduction}

The use of composite sandwich construction, consisting of thin-gage face sheets bonded to honeycomb or foam cores, is growing because it is an efficient method for increasing bending rigidity without necessarily increasing structural weight. Current applications include helicopter blades, optical benches for space applications, nonferrous ship hulls, and its use is rapidly increasing in future airframe designs [1]. In addition to rigidity, sandwich structures may have enhanced energy absorption capability and damage resistance when energy absorbing core materials are used. Cellular metals are an attractive class of materials for core structures for this reason. Not only are they extremely low-density and can exhibit high energy absorption but have an outstanding combination of mechanical, thermal, and acoustic properties $[2,3]$.

The right combination of rigidity, damage resistance, damage tolerance, and low density would open up a myriad of possible applications for these types of sandwich structures, including fan blade containment. The fan case in a jet engine is required to contain a fan blade in the rare event of a blade loss during operation. Currently, the fan cases in about half of the commercial engines simply consist of a metallic ring surrounding the fan rotor, which is thick enough to prevent part or all of a fan blade from penetrating the case [4]. The remainder of the fan containment systems have, in addition to a metallic ring, a large wrap of Kevlar or related material in order to contain the debris from a possible blade out. Regardless of the design, the fan case is the largest structural component in high-bypass-ratio turbofan engines used in commercial aircraft and can weigh over $500 \mathrm{~kg}$. Therefore, the use of lighter, stiffer, and more damage resistant hybrid composite structures would be advantageous in most 
engines and is considered a necessity in the latest generation of very large diameter, highbypass-ratio turbofan engines.

However, there are two major technical challenges to use of lightweight sandwich structures in fan containment applications. The first is to demonstrate that the lightweight sandwich structure can stop a failed blade from reaching the engine nacelle, in other words, to verify its impact damage resistance. The second challenge is to demonstrate that the fan case can maintain structural integrity after a blade-out incident, i.e. damage tolerance. Maintaining structural integrity is required to limit secondary damage caused by impact debris and to constrain out-of-balance motion of the rotor after the blade or blade fragment is lost in the engine.

Unfortunately, the majority of the technical literature on impact resistance of various materials has been dedicated to ordinance type applications involving impact speeds of 1000 $\mathrm{m} / \mathrm{sec}$ or higher. For typical fan containment applications, impact speeds are much slower, on the order of $200-400 \mathrm{~m} / \mathrm{sec}$, but are faster than can be studied using typical static material testing techniques. Furthermore, there is no reliable technique for predicting the impact performance of a simple metal, let alone a more complicated hybrid composite sandwich structure. Consequently, significant empirical testing in this area is necessary both to identify potential low-velocity impact resistant materials and structures and to develop the databases necessary for the development of predictive models. 
This study is part of a larger program designed to generate this needed experimental lowvelocity-impact data by screening new materials and hybrid composite concepts for ballistic damage resistance. The final goal is the identification of new materials and concepts for possible use in fan containment systems. In the work that follows, the ballistic limit was determined for 2024-T3 Al, GLARE-5 laminates, and various hybrid composite sandwich structures consisting of GLARE-5 face sheets and commonly available aluminum-based metallic core materials. Testing was performed consistent with screening tests performed previously on various metallic alloys [4] adding to the available NASA database.

\section{Materials}

Aluminum alloy 2024 is a very high-strength aluminum alloy commonly used in the aerospace industry. It is also one of the constituents of GLARE-5 laminates. Consequently, 2024-T3 $\mathrm{Al}$ was chosen as a baseline material for ballistic testing for comparison with the GLARE-5 laminates and hybrid sandwich composites. Al 2024-T3 plate was purchased in thicknesses of $0.4 \mathrm{~mm}$ to $6.4 \mathrm{~mm}$ and subsequently cut into ballistic test panels and tensile samples.

$\operatorname{GLARE}^{\circledR}$ (a GLAss fiber REinforced aluminum) is a family of fiber-metal laminates developed over the past two decades at The Delft University of Technology as a light weight, extremely damage-tolerant material for aerospace applications $[5,6]$. The particular grade of GLARE known as GLARE-5 is the result of an effort focused on optimizing the fiber/metal laminate concept for use in impact-prone structures. This material was developed specifically for aircraft fuselage structures and provides high fatigue resistance, and comparable or better 
damage tolerance and impact strength than straight aluminum alloys [7]. GLARE-5 laminates consist of thin high-strength 2024-T3 aluminum alloy sheets bonded together with biaxial S2glass fiber reinforced epoxy composite prepregs. Its constituent components and configuration are schematically illustrated in Figure 1.

Three $1.22 \mathrm{~m}$ wide by $2.44 \mathrm{~m}$ long sheets of GLARE-5, each sheet consisting of a different total panel thickness and lay-up scheme, were purchased from Aviation Equipment Structures Inc., Costa Mesa, CA. Table 1 lists the differences in structure between the three different sheets of GLARE-5 investigated and the nomenclature used in this paper to define the various GLARE-5 materials. These sheets were cut into impact test panels measuring $17.8 \times 17.8 \mathrm{~cm}$ squared. Ballistic impact tests were conducted on: i.) single GLARE-5 panels, ii.) two and three GLARE-5 panels bonded together by epoxy adhesive to create thicker laminates, and iii.) GLARE-5 panels as face sheets, which were part of a hybrid sandwich structure incorporating one of three different possible core materials. The three types of core materials used were (1) Hexcel Grade CR III honeycomb, (2) Al-12Si metallic foam, and (3) Al alloy lattice block material (LBM) castings from JAM Corp. These three core materials were chosen because of their relative availability in the size and quantity needed for this study and because they represent three distinctly different types of cellular structures.

The honeycomb was obtained from Hexcel Composites, Inc. The particular grade of material used was HexWeb ${ }^{\mathrm{TM}} \mathrm{CR}$ III ${ }^{\circledR} \mathrm{Al}$ honeycomb, which is composed of corrosion resistant, aerospace grade $5052 \mathrm{Al}$ alloy foil. The honeycomb had a hexagonal cell size of $4.76 \mathrm{~mm}$ and a foil gauge thickness of $0.038 \mathrm{~mm}$, resulting in a density of $0.07 \mathrm{~g} / \mathrm{cm}^{3}$ and a reported crush strength of $1.7 \mathrm{MPa}(250 \mathrm{psi})$ [8]. The honeycomb was received in sheets measuring 
$30.5 \mathrm{~cm}$ wide $x 61 \mathrm{~cm}$ long and $1.27 \mathrm{~cm}$ thick. These sheets were cut into $17.8 \mathrm{~cm} \times 17.8 \mathrm{~cm}$ x $1.27 \mathrm{~cm}$ thick panels and bonded between GLARE-5 face sheets.

The metallic foam used in this study was an Al-12Si alloy closed-cell metallic foam purchased from Fraunhofer USA, Center for Manufacturing and Advanced Materials, Newark, DE. The panels measured $17.8 \mathrm{~cm} \times 17.8 \mathrm{~cm}$, in thicknesses of 1.27 and $2.54 \mathrm{~cm}$, had a predominant pore size between 1 and $2 \mathrm{~mm}$ in diameter, and a density of approximately $0.5 \mathrm{~g} / \mathrm{cm}^{3}$ or about $20 \%$ of the original base alloy. These panels were produced by their patented [9] powder metallurgy technique. According to this process, commercial metal alloy powders are mixed with small quantities of a powdered foaming agent. The mixture is then compacted to a semi-finished product of low porosity by applying compaction techniques such as extrusion. The semi-finished compact of metal and foaming agent is then heated to near the melting point of the metal producing a homogeneous, closed-cell pore structure.

Lattice materials are another subset of cellular materials that derive multifunctional mechanical performance from their highly ordered internal truss-like structure. Two types of lattice material have been developed [2]. One has a pyramidal unit cell and is referred to as lattice block material (LBM) [10] and the other has a face-center tetragonal arrangement of nodes and is referred to as an octet truss material (OTM) [11]. The interlocked truss system of the lattice material results in good specific strength and stiffness along with remarkable damage tolerance [12]. The relative density of these materials can be engineered by choosing various ligament dimensions (length to width ratio) and truss angles. Additionally, structures can be configured with layers of different geometries and densities. Complicated components 
can be made directly to near-net shape by casting and other custom production methods. The LBM concept has already been applied to wide variety of parent materials including Alalloys, stainless steels, Be-based alloys, Cu-based alloys, and Ni-based superalloys by low cost sand casting and investment casting techniques $[13,14]$.

For this study, LBM panels of investment cast $\mathrm{Al}$ alloy $\mathrm{A}-254$, measuring $15.24 \mathrm{~cm}$ wide $\mathrm{x}$ $30.48 \mathrm{~cm}$ long $x 1.02 \mathrm{~cm}$ thick having one layer of ligaments approximately $0.16 \mathrm{~cm}$ in diameter were obtained from Jonathan Aerospace Materials Corp., Wilmington, MA [10]. The current LBM construction consisted of thin ligaments arranged in a three-dimensional triangulated truss-like structure with a $1.27 \mathrm{~cm}$ node spacing arranged in a square array. A detailed view of a section of a lattice block panel showing this structure is presented in Figure 2. After the gating was removed from the as-received LBM panels they were cut into two halves along the length and bonded between GLARE face sheets.

Panels of each of these core materials were bonded between GLARE-5 face sheets using Scotch Weld ${ }^{\circledR}$ Brand thermosetting epoxy structural adhesive film. Curing occurred in an autoclave at a temperature of $121{ }^{\circ} \mathrm{C}$ for 1 -hour and a pressure of $68.9 \mathrm{kPa}$. The temperature was ramped to the cure temperature and back to room temperature at a rate of $80^{\circ} \mathrm{C} / \mathrm{hr}$ while full pressure was applied over the entire three-hour run. To generate thicker GLARE only panels, multiple sheets of GLARE-5 were bonded together using this same process. 


\section{Experimental Procedures}

To determine whether static properties have any correlation with ballistic resistance, roomtemperature tensile properties were measured by testing dog-bone shaped tensile specimens in a screw-driven universal test machine equipped with hydraulic wedge grips. Tensile samples were cut from the $2024 \mathrm{Al}$-sheet and GLARE-5 panels by abrasive water-jet machining. The tensile samples were $15.24 \mathrm{~cm}$ in length overall with a $2.54 \mathrm{~cm}$ gauge length and a $36.83 \mathrm{~cm}$ radius that promotes deformation in the gauge section of composite materials such as the GLARE-5. The tensile tests were conducted under constant crosshead control at speeds of $0.0228 \mathrm{~cm} / \mathrm{sec}, 0.228 \mathrm{~cm} / \mathrm{sec}$ and $2.286 \mathrm{~cm} / \mathrm{sec}$. Strain was measured using a $2.54 \mathrm{~cm}$ gauge length extensometer.

Ballistic impact screening tests were conducted on these materials consistent with procedures described previously $[4,15]$. The impact tests were performed at room temperature using a

.50 caliber gas gun (Fig. 3a), which consists of a pressure vessel with a pressure capacity of $10 \mathrm{MPa}$ and a volume of $2250 \mathrm{~cm}^{3}$, connected via a high-speed solenoid valve to a stainless steel hollow barrel approximately $2 \mathrm{~m}$ long. The barrel has an outside diameter of $2.54 \mathrm{~cm}$ and an inside diameter of $1.28 \mathrm{~cm}$. Helium was used as the propellant. The velocity of the projectile immediately prior to impact was measured by the interruption of two laser beams a fixed distance apart, as shown schematically in Fig. 3b. The test panels were clamped on all sides between a steel "picture-frame" type fixture with a $15.24 \mathrm{~cm} \times 15.24 \mathrm{~cm}$ aperture, shown in Fig. 3c. The projectiles were Ti-6Al-4V (AMS 4928) cylinders, $2.54 \mathrm{~cm}$ long with a $1.27 \mathrm{~cm}$ diameter and a hardness of 36-37 HRC. A radius of $0.0813 \mathrm{~mm}$ was machined on 
the edge of the impacting face. As a final control, the mass of the projectiles was constrained between $14.05 \mathrm{~g}$ and $14.20 \mathrm{~g}$.

The overall test configuration was designed to best imitate the salient features of a blade out event. The selected clamping system was chosen to allow relatively large deflections in the test panel in order to mimic the behavior that would occur in a fan blade-out. Also, the test

panel is also subject to an impact by a 50 -calibur)blunt-nose projectile having relatively sharp edges representative of a fan blade segment. The ballistic limit was taken to be the minimum te with 8 . velocity required for perforation, where perforation is defined as the complete piercing of the target by the projectile. The ballistic limit for each material at a given areal weight was determined by conducting at least seven impact tests (if material permitted) at velocities selected such that some penetrated the specimens and some did not. The difference between the highest non-penetrating velocity and the lowest penetrating velocity was typically less than $5 \mathrm{~m} / \mathrm{sec}$ indicating that the ballistic limit was usually very well defined. Using this technique, it is estimated that the error in the ballistic limit is within $\pm 6 \mathrm{~m} / \mathrm{sec}$ [16].

\section{Results}

\subsection{Tensile properties of GLARE-5 laminates and other constituents}

In order to determine whether there is any relationship between static mechanical properties and ballistic performance, room temperature tensile tests were conducted on the GLARE-5 laminates and thin A1 2024-T3 sheet (one of the major constituents of GLARE-5). The results of these tests are summarized in Table 2, where each experimental value from this study represents the average and one standard deviation of at least three tensile tests. 
While there is a considerable range in tensile yield and ultimate strength values reported for 2024-T3 Al plate $[17,18]$, the material tested in this investigation fell within the middle of these reported values, Thus confirming that the $\mathrm{Al}$ alloy studied in this investigation was typical of 2024-T3.

Interestingly, the GLARE-5 exhibited lower yield strength, fracture strain, and modulus compared to straight 2024-T3 aluminum but exhibited a significantly higher ultimate tensile strength (UTS). These differences in mechanical behavior between the Al alloy and GLARE5 can be easily seen in the two representative stress strain curves shown in Figure 4 and can be attributed to the effect of the epoxy/fiber layers on the overall strength properties of the GLARE-5 laminate. The high-strength glass fibers, in particular, dominate the fracture behavior of the GLARE-5. Consequently, the GLARE-5 laminates exhibit a 30\% - 50\% increase in UTS over the aluminum alloy. However, while 2024-T3 aluminum sheet can easily exhibit $15 \%$ or more strain to failure with UTS and fracture stress occurring at the same value, the GLARE-5 exhibited a UTS at about $4.6 \%$ strain, which corresponds to the fracture strain of the glass fibers. At strains exceeding the fracture strain of the fiber, there is a very significant drop in stress, as the fibers rupture, though the aluminum layers are still able to carry some load (as shown in Fig. 4 for the GLARE-5 3/2 material). The exception to this behavior was the GLARE-5 (3/2b) samples (See Table 1 for a description of these materials), where failure of the fibers corresponded almost immediately to final failure of the laminate as the data in Table 2 indicates. 
Comparison of the various GLARE-5 laminate materials indicated that strength was proportional to the volume percent of the constituents present in the individual lay-ups (see

Table 1), such that the laminate with the greatest volume fraction of aluminum (GLARE-5 (2/1)) had the highest yield strength and the lowest UTS. Conversely, the GLARE-5 3/2b laminate had the highest volume fraction of glass-epoxy (lowest volume percent of $\mathrm{Al}$ ) and therefore, had the highest UTS of the three laminate configurations tested.

\begin{abstract}
Also, in the case of the GLARE-5 (3/2) the strength and strain to failure were essentially independent of strain rate over the two orders of magnitude variation tested. Only at the highest strain rate were yield and UTS even marginally higher, by just a few $\mathrm{MPa}$, than the lower rates, which can probably be attributed to a favorable high strain rate strengthening, which occurs in the glass fibers [5].
\end{abstract}

\title{
4.2 Impact resistance of 2024-T3 aluminum, GLARE-5, and hybrid sandwich
} structures:

Table 3 contains data on the ballistic properties of the materials tested. For purposes of this study the ballistic limit is defined as the lowest speed at which perforation of the test panel occurred. Also included in the table is the highest penetration speed recorded without perforation. The very close agreement between these two sets of numbers indicates the unambiguous manner in which the ballistic limit for these materials is defined given the sometimes restricted number of test samples per condition. 
Some of the ballistic limit data from Table 3 is also plotted in Figure 5 as a function of areal weight in order to more easily observe the relative performance of the various materials. These results indicate that the ballistic limit of single panels of GLARE- 5 with only $2 / 1$ or $3 / 2$ layups have comparable properties to that of plain $2024 \mathrm{Al}$ sheet. With increasing panel thickness (areal weight), however, the ballistic performance of the $2024 \mathrm{Al}$ alloy dramatically changes, with the slope of the ballistic limit versus areal weight curve decreasing with increasing areal weight. In reality, this curve should be thought of as composed of two different regions of behavior and was drawn with a smooth transition between the two regions. For low areal weights, less than about $8 \mathrm{~kg} / \mathrm{mm}^{2}$, the $\mathrm{Al}$ sheet fails primarily by ductile rupture of the panel preceded by significant plastic deformation of the sheet (left sample in Fig. 6). For areal weights greater than about $10 \mathrm{~kg} / \mathrm{mm}^{2}$, the failure of the Al plate is dominated by shear plugging (right sample in Fig. 6), a lack of global plasticity, and a ballistic limit - areal weight relationship with a much lower slope (as demonstrated in Fig. 5).

Since thicker GLARE-5 layups were unavailable, we had to approximate these by bonding several GLARE panels together. Consequently, the two panel version of GLARE-5 (3/2) can be thought of as a 5/4 layup with an extra layer of $\mathrm{Al}$ and the three panel version can be thought of as 7/6 layup with two extra layers of $\mathrm{Al}$ sheet. In contrast to the 2024-T3 $\mathrm{Al}$ alloy, the GLARE-5 (3/2) did not exhibit a change in ballistic performance with increasing areal weight over the range of weights tested (as shown in Fig. 5). Consequently, the performance of the GLARE-5 (3/2) exceeded that of the Al plate at higher areal weights, i.e., $20 \%$ better at an areal weight of approximately $18 \mathrm{~kg} / \mathrm{mm}^{2}$. GLARE-5's advantage over the 2024-T3 $\mathrm{Al}$ 
would increase even more as the areal weights increased further, assuming extrapolation of the current behaviors.

The GLARE panels impacted by the blunt projectile failed by shear plugging and petaling aided by limited debonding of the laminate layers as shown in Figure 7. On the front impacted side of the plate (Fig. 7a,b), high transverse shear stresses around the projectile result in circumferential cracking in front of the blunt projectile running perpendicular to the laminate layers. As the projectile continues through the panel, petaling then occurs as radial cracks initiate from the very high circumferential tensile forces [19] that also pass through the panel. These cracks run parallel to the laminate layers causing debonding (Fig. 7a). These debonded layers are then pushed up and out the way as the projectile continues through and out the backside of the panel resulting in the petalled appearance of the panel (Fig. 7c). This behavior was similar, regardless of the panel thickness or the total number of panels bonded together to form each test sample, with shear plugging always occurring on the front side of the panel and petaling occurring on the back-face.

We also tested two panels of GLARE-5 separated by a $12.7 \mathrm{~mm}$ air gap, for comparison to the samples composed of two bonded sheets of GLARE-5. This would allow each sheet of GLARE to deform and fracture independently of each other and would also represent the limit of a hybrid sandwich structure containing a core of no strength or weight. These results are summarized in Table 3. Based on this data, there was no change in ballistic limit when the panels were tested with a gap between them or when they were firmly bonded together, creating a thicker panel. In fact, for the GLARE-5 (3/2) the ballistic limit was $212 \mathrm{~m} / \mathrm{sec}$ 
when the two panels were firmly bonded together and $215 \mathrm{~m} / \mathrm{sec}$ when separated by a gap. In hindsight, this makes sense based on the fracture behavior of the impacted GLARE samples. The deformation of each sheet is already accommodated by debonding within the panels. Therefore, an additional gap is not needed to promote the global plasticity that is common to impacted thin samples.

The GLARE-5 (3/2) or (3/2b) was also used as the face sheets for hybrid sandwich panels with 12.7 and $25.4 \mathrm{~mm}$ thick $\mathrm{Al}-\mathrm{Si}$ alloy foam, $\mathrm{Al}$ honeycomb, and lattice block material cores. The results, summarized in Table 3 and highlighted in Figure 5, indicate that the sandwich structures composed of the Al-12Si foam cores exhibited the highest ballistic limit, of the hybrid sandwich structures tested, followed by the structures with the lattice block and honeycomb cores. However, the results were not encouraging. The hybrid structures, composed of GLARE-5 face sheets and honeycomb or LBM cores performed about the same as 2024- $\mathrm{T} 3 \mathrm{Al}$, based on areal weight. Finally, the best performing hybrid structures, containing the foam cores, were not even as good in ballistic impact resistance as the thick three-panel bonded version of the GLARE-5 (3/2).

\subsection{Effect of core structure on impact resistance of hybrid sandwich materials:}

The hybrid sandwich structures did not perform as well as hoped and except for the structures with the Al-foam cores, did not perform any better than two panels of GLARE-5 separated by a gap (or a core composed of nothing but air) (Table 3 ). This obviously indicates that the cores themselves did very little to absorb any of the energy of the penetrator. The reason for this becomes clear once a comparison is made between the basic cell dimensions of the core 
and the size of the penetrator. Simply put, the penetrator is impacting mostly air in the case of the hybrid sandwich materials containing the honeycomb and LBM cores. This is also evident from viewing the fractography of the impacted samples as shown in Figures 8 and 9.

The honeycomb is a non-homogenous material made up of large (relative to the size of the penetrator) hexagonal cells. For the sandwich structures containing the honeycomb core in this study, the penetrator can at best impact parts of 9-thin walled $(0.038 \mathrm{~mm})$ cells. The only mechanism for energy absorption inside the core is the crushing or buckling of these few immediate cells. Beyond the impact area there is little deformation of the honeycomb. As seen in Fig. 8, there is essentially no deformation of the honeycomb just a centimeter away from the impact zone. Therefore, there is very little material participating in the actual energy absorption process.

The same holds true for the sandwich structures with the LBM cores (Fig 9). In terms of the overall sandwich structure, the energy absorption by the core is limited to essentially the impact event area, Fig. 9a, and the shearing of the ligaments from a single node in the LBM (Fig. 9b). Very little deformation or damage outside the vicinity of the impact area, essentially of the diameter of the penetrator, was observed.

Only in the case of the GLARE-5 sandwich structures with the Al-foam cores was there any noticeable energy absorption by the core. As shown in Fig. 10, the foam cells deform significantly and compress under the impact load. Deformation is so severe that the foam immediately beneath the penetrator is actually compressed to almost full density. But there is 
also interaction with the surrounding core material. Half way through the $12.7 \mathrm{~mm}$ core, the foam starts to crack and tear creating a voided area extending several $\mathrm{cm}$ from the impact zone. This suggests that some of the impact energy was dispersed away from the projectile and absorbed by the foam core resulting in an additional increment of energy absorption over that provided by the GLARE face sheets.

\section{Discussion}

The physical phenomena that are observed during impact are dependent on the impact velocity, target and projectile material properties, and the size and geometry of the projectile and the target [20]. But in general the following impact regimes can be distinguished [21]: (1) an elastic, quasi-elastic regime that can be achieved by mechanical devices and drop weight testing machines for impact velocities of less than $50 \mathrm{~m} / \mathrm{s}$, (2) a regime of primarily plastic or viscous material response, for velocities in the range of $50-1000 \mathrm{~m} / \mathrm{s}$, where material strength still plays a significant role, (3) a fluid material response for impact velocities in the range of $1-3 \mathrm{~km} / \mathrm{s}$ where pressures approach or exceed the strength of the material, and (4) a hypervelocity regime for velocities exceeding about $3 \mathrm{~km} / \mathrm{s}$ where the major outcome of the collision is vaporization of the projectile and target.

Most impact research involves military projectiles designed to penetrate a structure or the development armor to withstand such penetrations with velocities in the upper end of regime 2 and above. However, for fan containment applications, we are actually interested in the lower end of region 2 , where there has been much less work. While the tip speed of a fan blade is somewhat faster, the center of mass travels at approximately $240-300 \mathrm{~m} / \mathrm{s}$. Within 
this velocity range, thick panels of GLARE-5 were found to provide the best impact resistance against perforation by a blunt nose projectile out of the materials and structures studied in this investigation.

There are several reasons for the superior behavior exhibited by the GLARE-5. First, the $2024 \mathrm{Al}$ exhibited a change in failure mode with increasing panel thickness (areal weight), that made it less competitive with GLARE-5 as the impact velocity increased. At low velocities, the impacts result in large global plastic deformation of the Al-panels with membrane stretching and petaling failure (Fig. 6a). This petaling is produced by the high radial and circumferential tensile stresses that develop after passage of the initial stress wave [19]. As the projectile passes into and through the plate the target bulges and then fails as the tensile strength of the material is exceeded and is then pushed aside as the projectile perforates the target.

As the impact velocity and thus the areal weight (thickness) of the Al plate needed to contain the projectile increases, however, the failure mode changes to plugging (Fig. 6b). This results in little or no global deformation of the panel. Instead, a cylindrical plug of material essentially the same diameter as the penetrator is pushed through the target. The separation of the plug from the target occurs either by void formation and growth by shear or by adiabatic shearing. During the latter process, instability occurs during plastic deformation of the material at a site of stress concentration. Additionally, the work of plastic deformation is converted almost entirely to heat. But due to the high deformation rates, the added temperature cannot dissipate away from the region of unstable plastic deformation fast 
enough, so that plastic flow in this localized region is further promoted. This process feeds upon itself until either the load is stopped or failure of the material occurs through intense shear bands. The energy extended with shear plugging is small compared to the amount of plastic work that can be dissipated in global deformation. This process is not as efficient in absorbing energy as petaling behaviors and thus the change in slope of the ballistic limit areal weight curve for the 2024-T3 Al alloy, shown in Figure 5.

Therefore, to optimize the design of a containment structure, it would be preferable to absorb all of the kinetic energy of the blade in global shell deformation and avoid localized perforation. In part, this is what is happening during failure of the GLARE laminates. Over the range of thicknesses tested, the failure mechanism was the same. It was a combination of shear plugging as the projectile entered the target, but then delamination of the GLARE allowed the various layers in the second half of the panel to act as independent thin sheets and deform globally resulting in large plastic deformations and petaling of the Al-layers (Fig. 7). Thus, due to the delamination of the individual layers in the GLARE-5, the failure mode was independent of panel thickness (areal weight).

The additional role of the glass fiber/epoxy layers in energy absorption, beyond acting as a delaminating surface, is not clear from the present results. Of course, the glass fibers are added to the material, foremost as a crack arrester for enhanced fatigue properties, but also for augmented impact resistance [5,6]. But at low velocities the GLARE-5 and a single panel of 2024-Al, in general, had similar impact resistance on an areal weight basis. It was only due to a change in fracture behavior of the 2024 aluminum, from global deformation to a low energy 
shear failure mechanism with increasing areal weight, that the GLARE-5 exhibited an advantage in impact resistance.

Analyzing damage modes in fiber composites is complex because it is a combination of failures of the various constituents: fiber breakage, fiber-matrix debonding, matrix cracking, and delamination. Impact damage in thick laminates is usually a combination of resin shear fracture and interlaminar delamination, while in thin laminates, such as those that make up the glass fiber/epoxy layers of GLARE, damage will be dominated by fiber failure. But GLARE is different. Instead of just multiple laminates or layers of glass fiber/epoxy like a conventional fiber reinforced material, there are alternating layers of aluminum sheet, as well, forming a hybrid laminate. Identifying all the contributing energy absorbing mechanisms responsible for the impact resistance of GLARE is problematic but necessary if one is to optimize the impact resistance of this material system. The potential role of the glass fibers in energy absorption, if any, and optimization of the GLARE architecture will be examined in future work.

The other purpose of this study was to determine whether there would be any benefits in using hybrid sandwich structures in fan containment applications. Unfortunately, the potential of these types of concepts can not be judged based on the current screening tests conducted in this study. As previously explained in the Results, the core structures, except for the Al-foam, had a cell or node size that was quite large relative the size of the projectile such that the projectile did not encounter significant resistance as it passed through the structures. In the case of the honeycomb, the few cells that were encountered were easily crushed (Fig. 8) while 
the LBM ligaments surrounding a single node were easily sheared (Fig. 9). The hybrid structures containing Al-foam cores did show some promise for containment applications compared to the solid $2024 \mathrm{Al}$ plates. But there was no advantage of the hybrid structure over equivalent areal weights of GLARE-5 (3/2).

While the small panel tests provide a convenient way to rank the impact performance of various materials, caution should also be used in analyzing the results. For example, future screening of the hybrid sandwich structures will have to be performed with full size blade simulating projectiles that will provide a more realistic relationship between the size of the projectile and the cell size in the core. Even for homogeneous materials, where it is possible to scale the displacement, contact forces, and strains from a small test to a larger prototype, scaling of impact damage is still problematic. A change in any one of the many factors that affect impact failure mode (i.e. velocity, target and projectile material properties, size and geometry) could result in significantly unexpected test results as the test is scaled up. Therefore, subcomponent or component testing is always necessary. Results of the small panel tests are useful, however, as a guide in down-selecting possible candidate materials and concepts such as identification in this study of the advantages of producing a containment system from a thick GLARE-like structure.

Finally, it was hoped that some relationship would exist between easily determined static properties such as tensile properties and impact resistance, which could be used as a crude screening guide for new materials. No obvious relationship was observed in this case. While the tensile properties for the GLARE-5 were quite disparate from that of the 2024 aluminum, 
their impact resistance was similar at low impact velocities and only through a change in impact fracture behavior of the aluminum, did GLARE-5 exhibit better properties at higher impact velocities. There was nothing in the tensile data that would have predicted or could have been used to rank the relative impact resistance of the materials studied in this case, especially as a function of areal weight.

\section{Summary and Conclusions}

Several lightweight hybrid sandwich structures have undergone screening tests for impact resistant applications. Even though GLARE-5 laminates were used as the face sheets on these hybrid sandwich concepts, simply a thick panel of GLARE-5 exhibited the highest ballistic limit of all the materials and concepts tested. It was superior to 2024-T3 $\mathrm{Al}$ (a major component of GLARE-5) at higher areal weights because the GLARE-5 did not exhibit a change in failure mode, from global plastic deformation and petaling to shear dominated plugging, as observed with the 2024-T3 Al alloy. This was due to delamination of the GLARE-5 laminate that allowed each of the individual Al layers to deform independently as thin sheets.

While the hybrid sandwich structures did not perform as well as hoped, they can not be totally ruled out as a viable concept by these screening tests, since there was an unrealistic relationship between cell and node size of the honeycomb and LBM core structures, respectively, and the size of the projectile. A more realistic screening test, where the projectile and core structure are proportional to their actual component size, will need to be developed for these types of hybrid structures. 


\section{Acknowledgements}

Useful and provocative conversations with $\mathrm{M}$. Pereira and S. Padula and the project guidance of D. Hopkins are gratefully acknowledged. The authors also wish to thank A. TeneterisNoebe and B. Lerch for their thoughtful reviews of this paper. This work was supported by the Ultrasafe project at NASA Glenn Research center. Special thanks to NDN.

\section{References}

1. J. Tomblin, et al.: "Review of Damage Tolerance for Composite Sandwich Airframe Structures," DOT/FAA/AR-99/49, August 1999.

2. A.G. Evans, J.W. Hutchinson, N.A.Fleck, M.F. Ashby, and H.N.G. Wadley: "The topological design of multifunctional cellular materials," Prog. Mater. Sci., 2001, 46, pp. 309-327.

3. J. Barnhart: "Manufacture, characterization and application of cellular metals and metal foams," Prog. Maters. Sci., 2001, 46, pp. 559-632.

4. G. Roberts and D. Revlock: "Impact testing of composites for aircraft engine application," NASA-TM 20001-21088, April 2001.

5. A.Vlot, L.B. Vogelesang, and T.J. de Vries: "Towards application of fibre metal laminates in large aircraft," Aircraft Eng. Aerospace Tech., 1999, 71, pp. 558-570.

6. A. Vlot: "Impact Properties of Fibre Metal Laminates," Comps. Eng., 1993, 3, pp. 911927.

7. L.B. Vogelesang and A. Volt: "Development of fibre metal laminates for advanced aerospace structures," J. Maters. Process. Tech., 2000, 103, pp. 1-5. 
8. HexWeb ${ }^{\mathrm{TM}} \mathrm{CR}^{\circledR}$ III Honeycomb Data Sheet 2100, Hexcel Composites, Dublin CA, January, 2001.

9. J. Baumeister and H. Schrader: "Methods for manufacturing foamable metal bodies," Patent No. 5,151,246, Sept., 1992.

10. Jonathan Aerospace Materials Technology Website: http:/www.jamcorp.com/, 2002.

11. N. Wicks and J.W. Hutchinson: “Optimal truss plates," Inter. J. Solids Struct., 2001, 38, pp. 5165-5183.

12. J.C. Wallach and L.J. Gibson: "Defect sensitivity of a 3D truss material," Scripta Mater., 2001, 45, pp. 639-644.

13. M.L. Renauld, A.F. Giamei, M.S. Thompson, J. Priluck: "Porous and cellular materials for structural applications," in Porous and Cellular Materials for Structural Applications, Editors: D.S. Schwartz, D.S. Shih, H.N.G. Wadley, and A.G. Evans, MRS Symp. Proc. Vol. 521, 1998, pp. 109-115.

14. M.G. Hebsur: "Processing of IN-718 Lattice Block Castings," in Processing and Properties of Lightweight Cellular Metals and Structures," Editors: A. Ghosh, T. Sanders, D. Claar, The Minerals, Metals \& Materials Society, Warrendale, PA, 2002, pp. 85-96.

15. D. M. Revilock and J. M. Perreira: "Ballistic Impact Performance of Metals for High Temperature Jet Engine Fan Containment Applications," in Thermal Hydraulic, Liquid Sloshing, Extreme Loads, and Structural Response - 2001, Editor: F.J. Moody, ASME 2001, pp. 69-76.

16. J.M. Pereira and B. Lerch: "Effects of heat treatment on the ballistic impact properties of Inconel 718 for jet engine fan containment applications," Inter. J. Impact Engin., 2002, 25, pp. 715-733. 
17. J.G. Gilbert: in Properties of Aluminum Alloys, ASM International, Metals Park, OH, 1999, p. 44.

18. ALCOA 2024 Plate, in Alloy Digest, ASM International, Metals Park, OH, 1999, filing code: Al-372.

19. M.S. Hoo Fatt and K. S. Park: "Dynamic models for low-velocity impact damage of composite sandwich panels - Part A: Deformation," Comp. Struct., 2001, 52, pp. 335351.

20. G.G. Corbett, S.R. Reid, and W. Johnson: "Impact Loading of Plates and Shells by FreeFlying Projectiles: A Review," Int, J. Impact Engng., 1996, 18, pp. 141-230.

21. J.A. Zukas: "Penetration and Perforation of Solids, in Impact Dynamics, Editors: J.A. Zukas, et al., Krieger Publishing Co., Malabar, FL, 1992, pp. 155-214. 


\section{Figure Captions}

Figure 1. Schematic configuration of GLARE-5 laminates. Shown is a 2/1 lay-up.

Figure 2. An investment cast A-254 aluminum LBM panel showing the typical triangular truss structure that is characteristic of lattice block materials.

Figure 3. NASA Glenn's .50 caliber impact lab. a.) Overview of the .50 caliber gas gun setup, b.) schematic illustration of the dual laser system used for measuring projectile velocity prior to impact (located between the end of the barrel and the test fixture), and c.) $15.24 \mathrm{~cm}$ aperture test fixture used for holding samples in position for testing.

Figure 4. Representative tensile stress-strain curves for 2024-T3 aluminum and GLARE-5.

Figure 5. Ballistic limit for various materials and hybrid sandwich structures as a function of areal weight.

Figure 6. Thin $(3.2 \mathrm{~mm})$ and thick $(6.4 \mathrm{~mm}) 2024 \mathrm{Al}$ panels tested just below the ballistic limit and sectioned through the center of the impact zone and viewed edge on. The thin panel (Left) shows significant global plastic deformation of the panel. The thick panel (Right) shows little global deformation with deformation and fracture dominated by shear plugging.

Figure 7. a.) Cross-section of an impacted two-panel bonded GLARE-5 3/2 sample showing delamination of the layers. b.) Shear plugging is evident on the front face of the panel and $c$.) Dishing and petaling is evident on the back face of the sample due to the delamination shown in part a.

Figure 8. Cross-section showing a projectile penetrating into a GLARE-5 (3/2b)/honeycomb hybrid sandwich panel.

Figure 9. a.) Cross-section showing a projectile penetrating into a GLARE-5 (3/2)/LBM hybrid sandwich panel. b.) Perforated LBM structure showing the limited region (essentially a single node) impacted by the projectile.

Figure 10. Cross-section showing a projectile penetrating into a GLARE-5 (3/2)/1.27 cm thick Al-foam core hybrid sandwich panel. 


\section{Table 1}

GLARE-5 Laminate Configurations Investigated.

\begin{tabular}{|l|c|c|c|c|}
\hline Specimen I.D. & $\begin{array}{l}\text { Al/Glass-Epoxy } \\
\text { layer ratio }\end{array}$ & $\begin{array}{l}\text { Total Panel } \\
\text { thickness mm } \\
\text { (inches) }\end{array}$ & $\begin{array}{l}\text { 2024-T3 Al layer } \\
\text { thickness mm } \\
\text { (inches) }\end{array}$ & $\begin{array}{l}\text { Vol.\% Al in } \\
\text { the laminate }\end{array}$ \\
\hline GLARE-5 (3/2) & $3 / 2$ & $2.54(0.100)$ & $0.51(0.020)$ & $60 \%$ \\
\hline GLARE-5 (3/2b) & $3 / 2$ & $1.93(0.076)$ & $0.30(0.012)$ & $47 \%$ \\
\hline GLARE-5 (2/1) & $2 / 1$ & $1.50(0.059)$ & $0.51(0.020)$ & $66 \%$ \\
\hline
\end{tabular}


Table 2

Tensile Properties for 2024-T3 Al and GLARE-5 Laminates*

\begin{tabular}{|l|l|c|c|c|c|c|}
\hline \multicolumn{1}{|c|}{ Material } & $\begin{array}{c}\text { Strain } \\
\text { Rate } \\
(\mathrm{s}-1)\end{array}$ & $\begin{array}{c}0.2 \% \text { Offset } \\
\text { Yield } \\
\text { Strength } \\
\text { (MPa) }\end{array}$ & $\begin{array}{c}\text { UTS } \\
\text { (MPa) }\end{array}$ & $\begin{array}{c}\text { Strain at } \\
\text { UTS (\%) }\end{array}$ & $\begin{array}{c}\text { Fracture } \\
\text { Strain (\%) }\end{array}$ & $\begin{array}{c}\text { Modulus } \\
\text { (GPa) }\end{array}$ \\
\hline 2024-T3 Al (0.5 mm thick) & 0.015 & $320 \pm 3$ & $472 \pm 3$ & $15.2 \pm 0.6$ & $15.2 \pm 0.6$ & $74.0 \pm 1.8$ \\
\hline 2024-T3 Al [16] & & 345 & 485 & & 17 & 72 \\
\hline 2024-T3 Al (0.2-6.3 mm)[17] & & 289 & 441 & & $10-15$ & \\
\hline & & & & & & \\
\hline GLARE-5 (3/2) & 0.0015 & $270 \pm 3$ & $751 \pm 11$ & $4.7 \pm 0.1$ & $7.1 \pm 0.8$ & $57.2 \pm 2.3$ \\
\hline GLARE-5 (3/2) & 0.015 & $274 \pm 2$ & $747 \pm 6$ & $4.7 \pm 0.1$ & $6.7 \pm 2.8$ & $57.2 \pm 1.5$ \\
\hline GLARE-5 (3/2) & 0.15 & $289 \pm 8$ & $789 \pm 8$ & $4.9 \pm 0.1$ & $9.6 \pm 1.1$ & $56.3 \pm 0.6$ \\
\hline & & & & & & \\
\hline GLARE-5 (3/2b) & 0.0015 & $249 \pm 4$ & $810 \pm 16$ & $4.4 \pm 0.1$ & $4.7 \pm 0.5$ & $52.8 \pm 1.6$ \\
\hline GLARE-5 (3/2b)** & & $252 \pm 7$ & $803 \pm 15$ & & & \\
\hline $\begin{array}{l}\text { GLARE-5 (3/2b)(2 panels } \\
\text { bonded together) }\end{array}$ & 0.015 & $266 \pm 7$ & $809 \pm 14$ & $4.4 \pm 0.1$ & $4.4 \pm 0.1$ & $52.6 \pm 1.0$ \\
\hline $\begin{array}{l}\text { GLARE-5 (3/2b) (2 panels } \\
\text { bonded together) }\end{array}$ & 0.15 & $280 \pm 21$ & $828 \pm 16$ & $4.6 \pm 0.1$ & $4.8 \pm 0.3$ & $51.3 \pm 0.2$ \\
\hline & & & & & & \\
\hline GLARE-5 (2/1) & 0.0015 & $282 \pm 1$ & $664 \pm 13$ & $4.3 \pm 0.2$ & $8.7 \pm 0.8$ & $59.7 \pm 1.0$ \\
\hline GLARE-5 (2/1)** & & $262 \pm 40$ & $651 \pm 69$ & & & \\
\hline
\end{tabular}

*Experimental values from this study are the average and one standard deviation of three tests.

**Previously unpublished data courtesy of J.W. Evancho, Aviation Equipment, Inc., Gibsonia, PA.

The data represent the average and one standard deviation of at least nine test samples. 
Table 3

Ballistic Properties of 2024 Aluminum, GLARE-5 Laminates, Various Hybrid Structures

\begin{tabular}{|l|c|c|c|c|c|}
\hline \multicolumn{1}{|c|}{ Material } & $\begin{array}{c}\text { Panel } \\
\text { Thickness } \\
(\mathrm{mm})\end{array}$ & $\begin{array}{c}\text { Areal } \\
\text { Weight } \\
\left(\mathrm{kg} / \mathrm{m}^{2}\right)\end{array}$ & $\begin{array}{c}\text { Ballistic Limit } \\
\text { (Lowest recorded } \\
\text { Perforation Speed }) \\
(\mathrm{m} / \mathrm{sec})\end{array}$ & $\begin{array}{c}\text { Highest Speed } \\
\text { recorded without } \\
\text { perforation } \\
\text { (m/sec) }\end{array}$ \\
\hline GLARE-5 (2/1) & 1.53 & 3.74 & 9 & 136 & 136 \\
\hline GLARE-5 (3/2b) & 1.93 & 4.43 & 7 & 151 & 150 \\
\hline GLARE-5 (3/2) & 2.54 & 6.24 & 8 & 156 & 155 \\
\hline GLARE-5 (3/2b) 2-panels bonded & 4.02 & 9.38 & 6 & 185 & 179 \\
\hline GLARE-5 (3/2b) 2-panels w/12.7 mm air gap & 16.56 & 8.87 & 7 & 203 & 199 \\
\hline GLARE-5 (3/2) 2-panels bonded & 5.30 & 12.70 & 7 & 212 & 206 \\
\hline GLARE-5 (3/2) 2-panels w/12.7 mm air gap & 17.78 & 12.50 & 17 & 215 & 222 \\
\hline GLARE-2 (3/2) 3-panels bonded & 7.95 & 18.90 & 8 & 267 & 273 \\
\hline GLARE-5 (3/2b) w/Honeycomb core & 18.65 & 10.84 & 8 & 195 & 200 \\
\hline GLARE-5 (3/2) w/LBM core & 17.20 & 17.92 & 7 & 221 & 221 \\
\hline GLARE-5 (3/2b) w/12.7 mm Al Foam core & 16.85 & 16.50 & 5 & 244 & 244 \\
\hline GLARE-5 (3/2) w/12.7 mm Al Foam core & 18.05 & 20.12 & 2 & $>256$ & 256 \\
\hline GLARE-5 (3/2b) w/25.4 mm Al Foam core & 29.50 & 22.95 & 5 & 240 & 235 \\
\hline Aluminum 2024-T3 & 0.40 & 1.11 & 14 & 67 & 70 \\
\hline Aluminum 2024-T3 & 1.60 & 4.38 & 13 & 131 & 132 \\
\hline Aluminum 2024-T3 & 3.20 & 8.83 & 7 & 196 & 192 \\
\hline Aluminum 2024-T3 & 6.40 & 18.31 & 11 & 213 & 217 \\
\hline
\end{tabular}




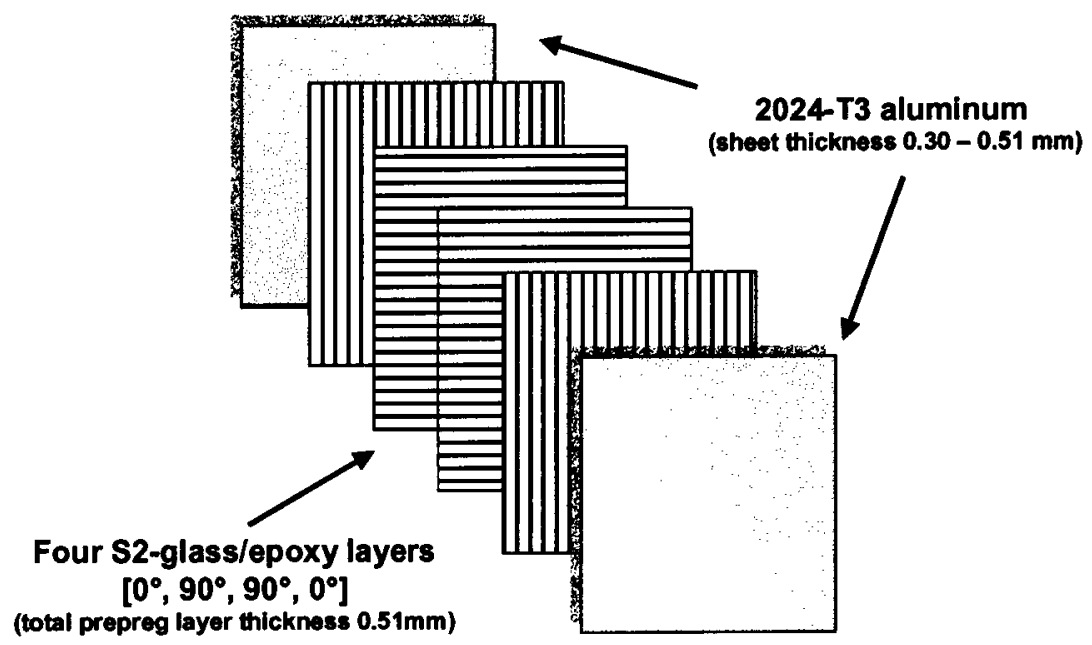

Figure 1. Schematic configuration of GLARE-5 laminates. Shown is a 2/1 lay-up. 


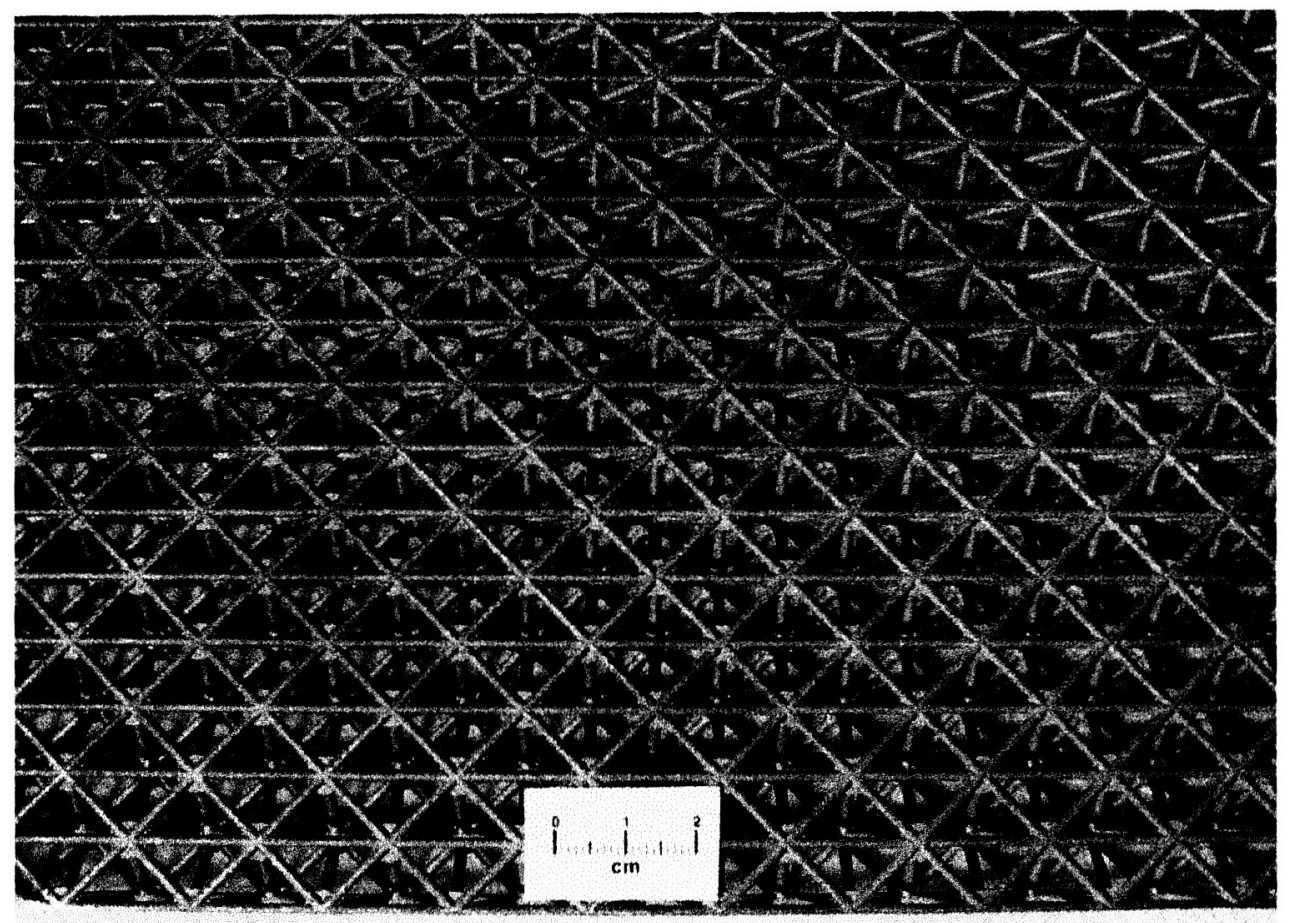

Figure 2. An investment cast A-254 aluminum LBM panel showing the typical triangular truss structure that is characteristic of lattice block materials. 
a.

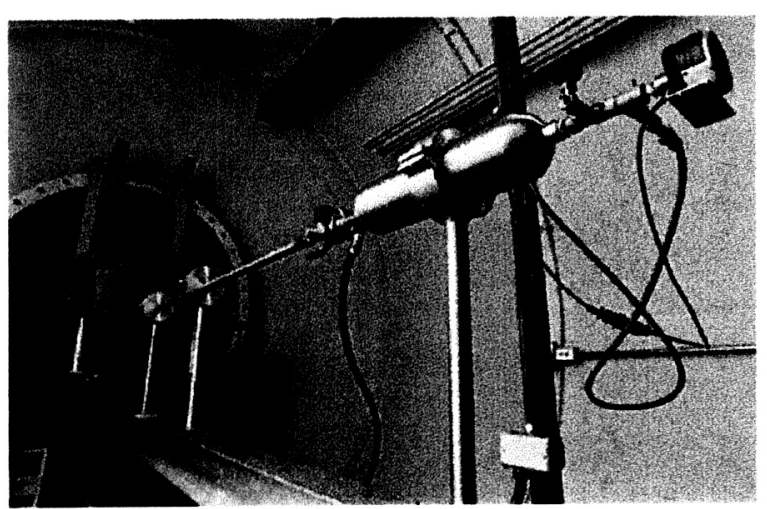

b.

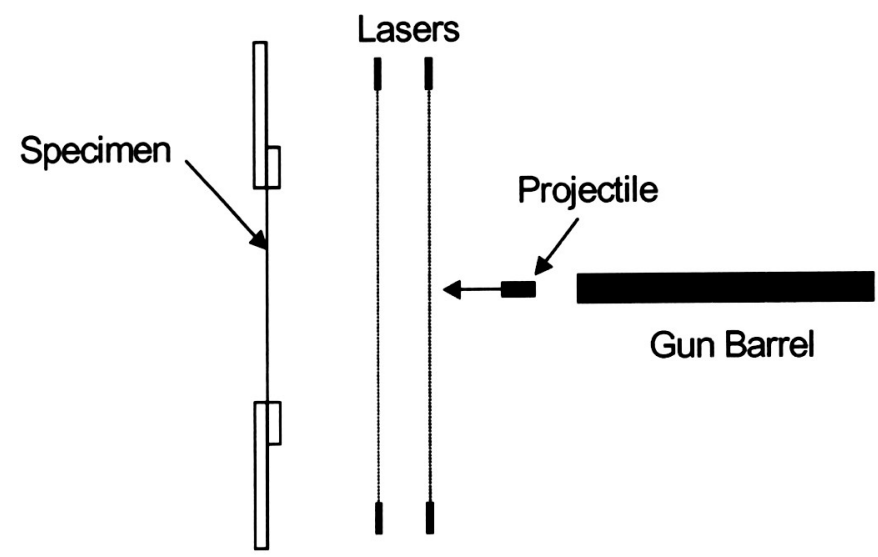

c.

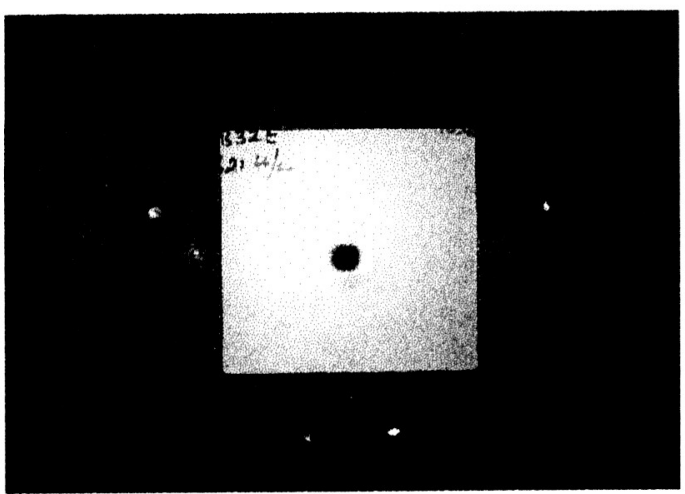

Figure 3. NASA Glenn's 50 caliber impact lab. a.) overview of the 50 caliber gas gun setup, b.) schematic illustration of the dual laser system used for measuring projectile velocity prior to impact (located between the end of the barrel and the test fixture), and c.) $15.24 \mathrm{~cm}$ aperture test fixture used for holding samples in position for testing. 


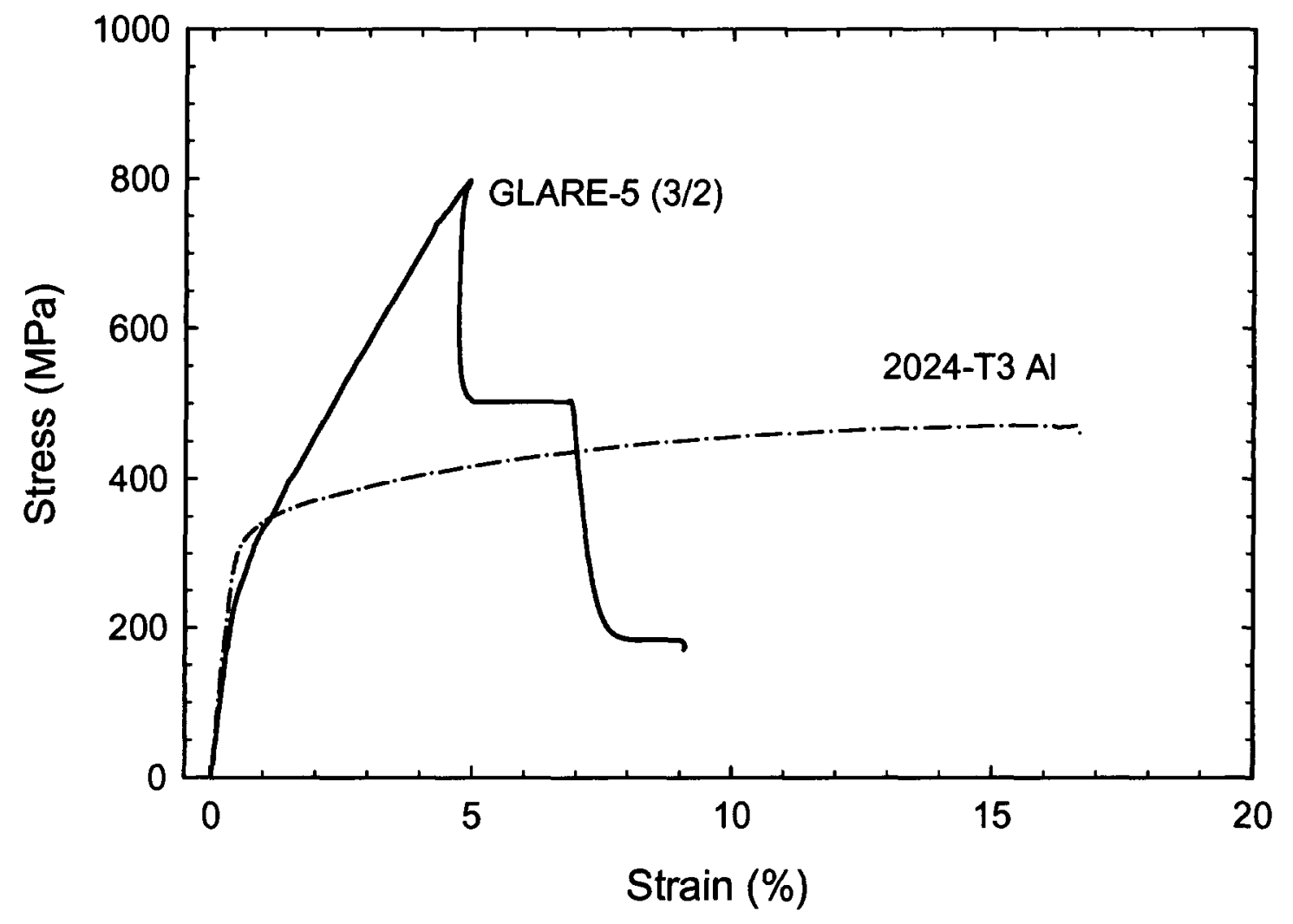

Figure 4. Representative tensile stress-strain curves for 2024-T3 aluminum and GLARE-5. 


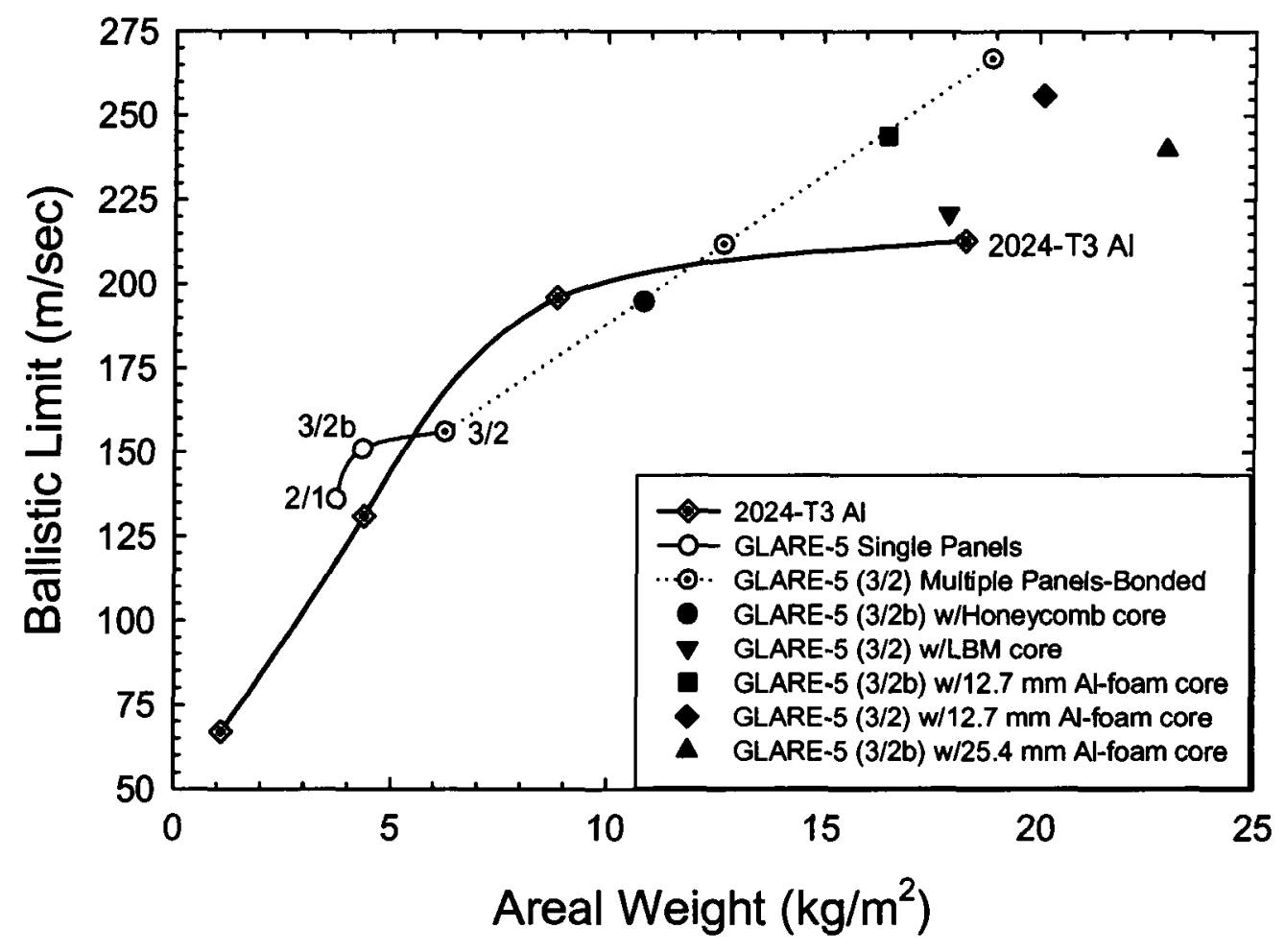

Figure 5. Ballistic limit for various materials and hybrid sandwich structures as a function of areal weight. 


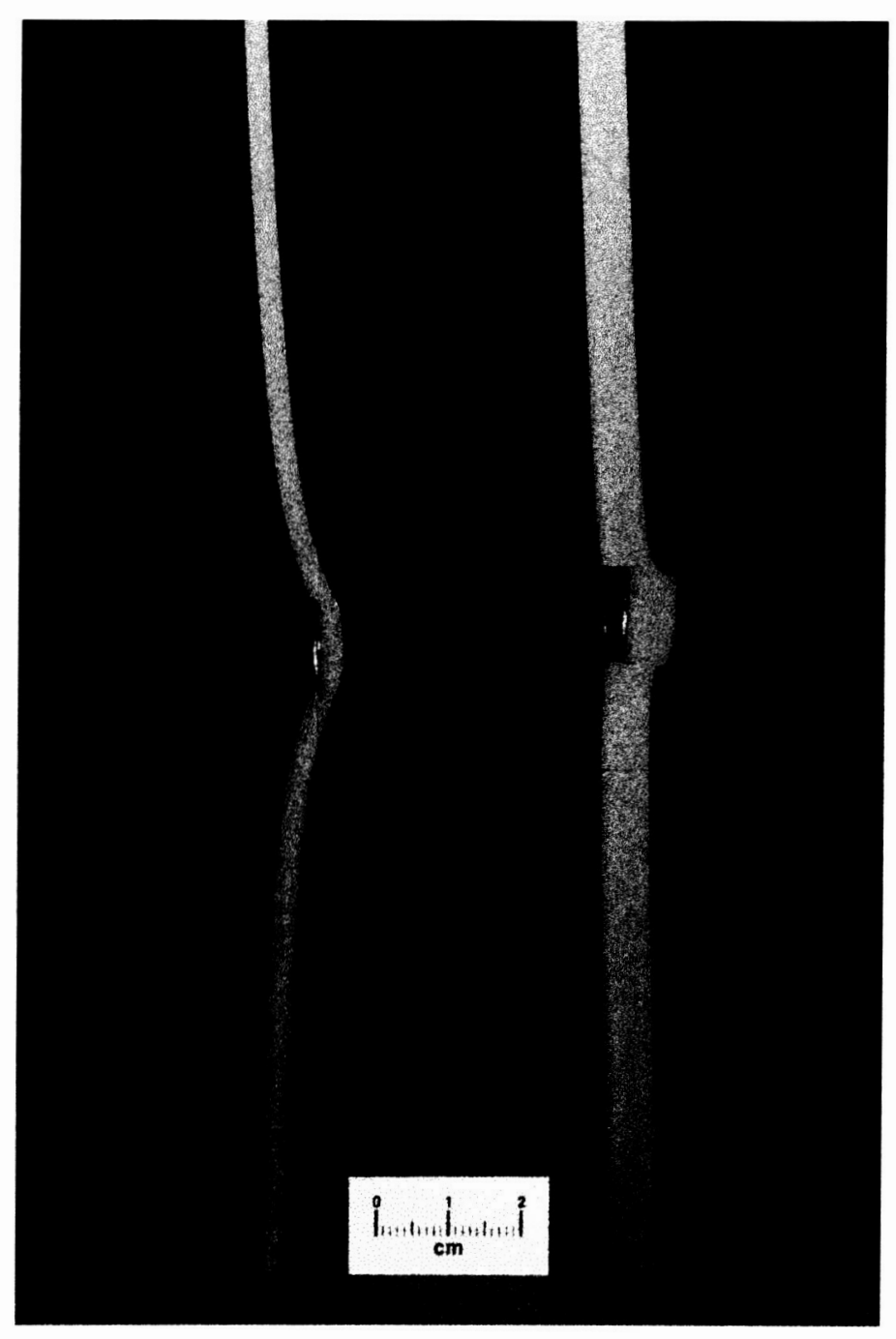

Figure 6. Thin $(3.2 \mathrm{~mm})$ and thick $(6.4 \mathrm{~mm}) 2024 \mathrm{Al}$ panels tested just below the ballistic limit and sectioned through the center of the impact zone and viewed edge on. The thin panel (Left) shows significant global plastic deformation of the panel. The thick panel (Right) shows little global deformation with deformation and fracture dominated by shear plugging. 
a.

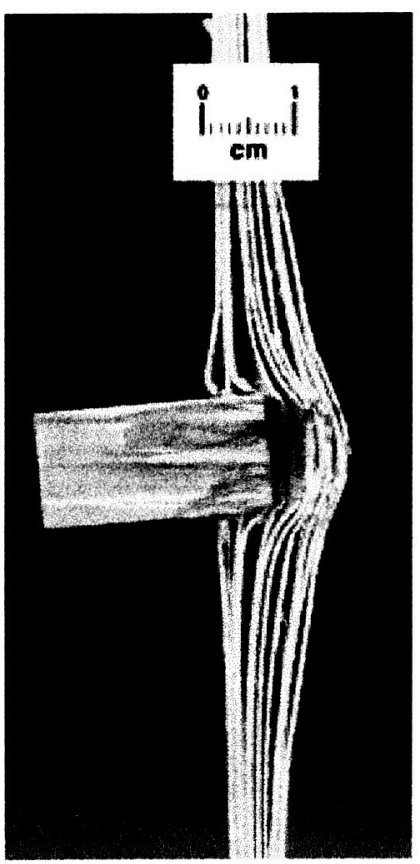

b.

c.
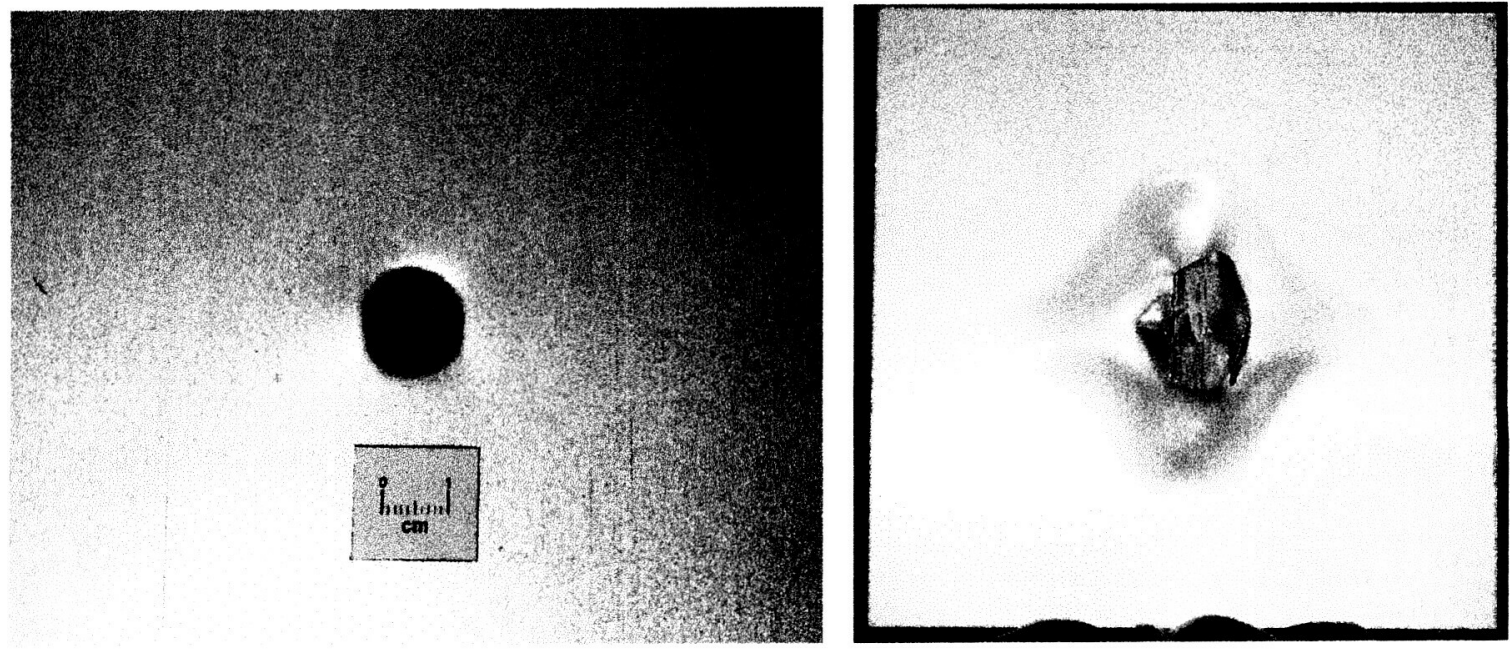

Figure 7. a.) a.) Cross-section of an impacted two-panel bonded GLARE-5 3/2 sample showing delamination of the layers. b.) Shear plugging is evident on the front face of the panel and c.) Dishing and petaling is evident on the back face of the sample due to the delamination shown in part a. 


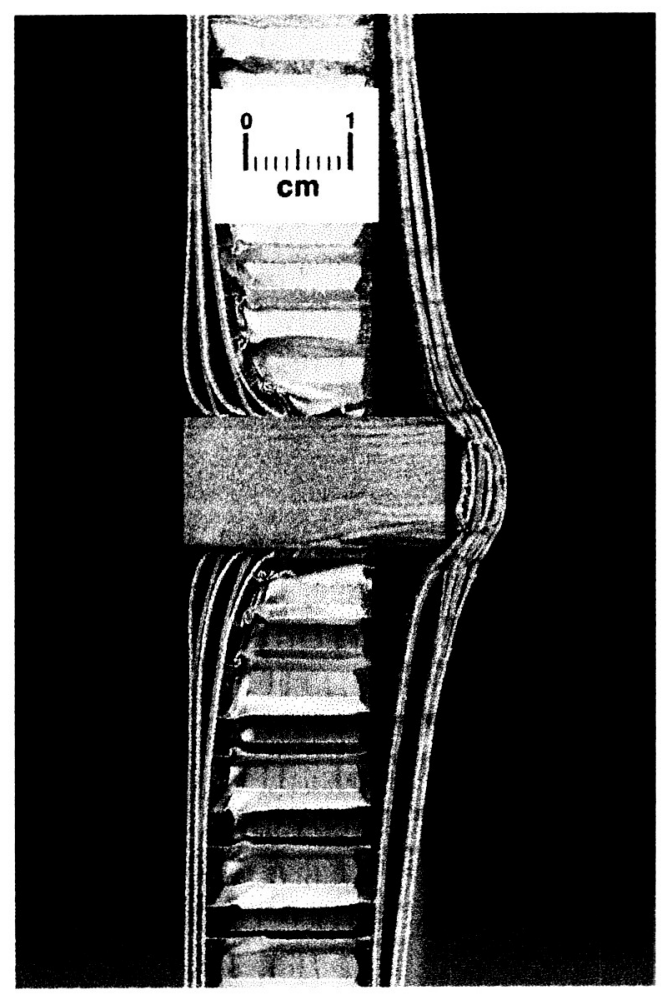

Figure 8. Cross-section showing a projectile penetrating into a GLARE-5 (3/2b)/honeycomb hybrid sandwich panel. 
a.

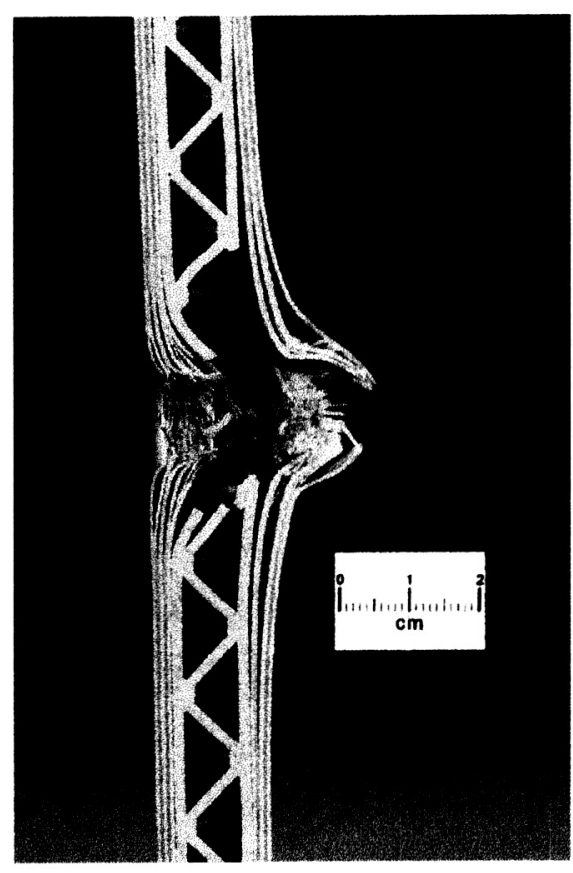

b.

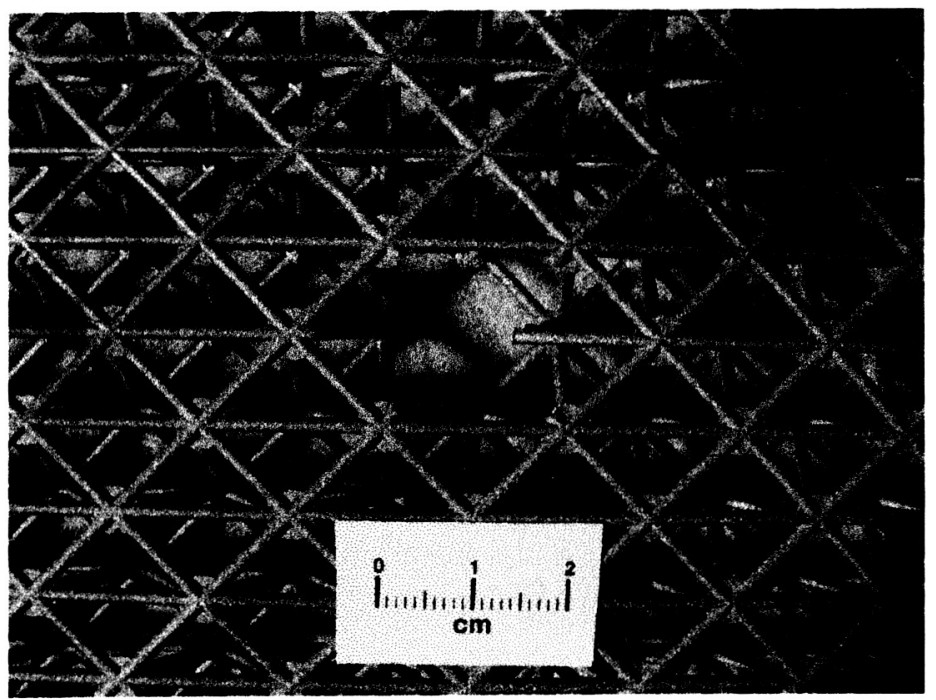


Figure 9. a.) Cross-section showing a projectile penetrating into a GLARE-5 (3/2)/LBM hybrid sandwich panel. b.) Perforated LBM structure showing the limited region (essentially a single node) impacted by the projectile.

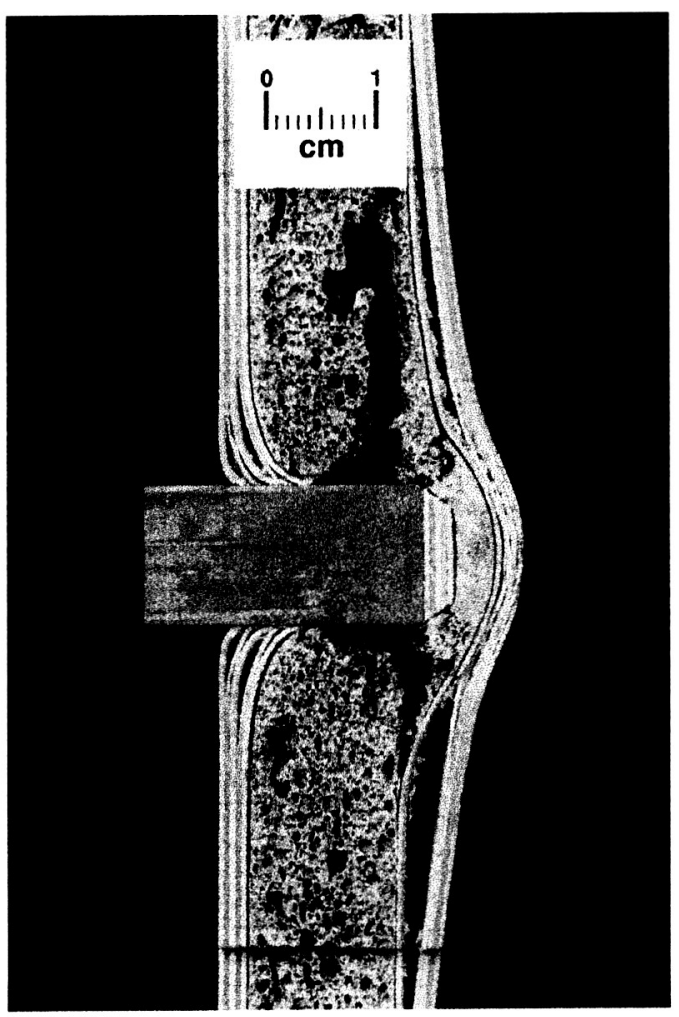

Figure 10. Cross-section showing a projectile penetrating into a GLARE-5 (3/2)/1.27 cm thick Al-foam core hybrid sandwich panel. 